\title{
Променлива обонятелна чувствителност и нарушена обонятелна перцепция при алергичен ринит
}

\author{
Н. Цаков \\ УМБАЛ "Царица Йоанна" - София \\ Катедра по оториноларингология, УМБАЛ "Царица Йоанна" - София
}

Резюме:

Цел: Да се характеризира връзката между алергичния ринит, тежестта и продължителността на носното заболяване, обонятелната функция и анамнестичните данни, включващи флуктуации или нарушения на обонятелното възприятие.

Модел на проучването: Оценка на обонятелната функция и носната симптоматика на 90 пациенти с алергичен ринит.

Място на проучването: УМБАЛ „Царица Йоанна - ИСУЛ“, Клиника по УНГ-болести.

Пациенти: 60 пациенти от УМБАЛ „Царица Йоанна - ИСУЛ“ с позитивни тестове за алергия и 30 деца - пациенти на доц Переновска от Детска клиника при УМБАЛ „Александровска“ (деца на възраст от 4 до 14-годишна възраст), от които 7 са с алергичен ринит, а 23 с алергичен ринит и бронхиална астма, като всички са без хроничен риносинуит или носни полипи. Пациентите от УМБАЛ „Царица Йоанна - ИСУЛ“ бяха групирани съобразно техния УНГ статус (30 пациенти без хроничен риносинуит или носна полипоза, 14 пациенти с хроничен риносинуит, но без полипи и 16 пациенти с носни полипи). Метод: Снеха се анамнестични данни за обонятелни нарушения, след което се проведе субективно обонятелно тестуване с олфактометьра на Димов-Райков, позволяващ оценката на минималните праговете на усет и разпознаване за пет мирисни субстанции, съотв. цитрал (лимон), гераниол (роза), ацетоацетат (оцет), ментол (мента) и терпениол (миризма на терпентин). Олфактометърът на Димов-Райков включва в набора от тестови миризми и хлороформ, но пред вид че се изследваха и деца, последният не бе използван при субективното определяне на обонятелната функция.

Резултати: Пациентите от УМБАЛ „Александровска“ (тяхната група бе наречена „УМБАЛА“) бяха диагностицирани като нормосмици, а тези от УМБАЛ „Царица Йоанна - ИСУЛ“ (групата УМБАЛЦИ) като хипо- и аносмични, като тежестта на обонятелните разстройства нарастваше. Сравнението с данни от здрави пациенти потвърди, че наблюдаваните резултати от обонятелното изследване при всички групи пациенти бяха сигнификантно по-слаби от очакваните за тяхната възраст. Анамнестичните данни за загуба на обонянието нарастваха корошно изследване върху ефективността на
топикалната кортикостероидна терапия при
аносмия у пациенти с тежко синуназално заболяване подсказва, че носната обструкция не е единствената причина за загубата на обоняние при тези пациенти ${ }^{1}$. В хода на лечението симптомите на заболяването (задебеляване на лигавицата, полипоидна дегенерация и полипоза) са намалели значително при всички пациенти. Обонятелната функция обаче се е подобрила значително при 59\% от болните, а при 41\% не е настъпила никаква промяна ${ }^{1}$. Един от индикаторите за успешно лечение на обонятелното нарушение са анамнестичните данни на болните за флуктуации в обонятелното възприятие, които могат да бъдат интерпретирани като показател за функциониращ обонятелен епител при иначе аносмичен пациент ${ }^{1}$.

Изкривеното възприятие на миризмите (паросмия) е друг симптом, докладван от болните със загуба на обонянието, особено при тези, чиито обонятелни проблеми са започнали след травма на главата или след прекарано възпаление на горните дихателни пътища ${ }^{2-5}$. В случая с аносмичните пациенти с ЧМТ оплакванията от паросмия бяха интерпертирани като отражение на регенераторни процеси в обонятелните връзки, вещаещи скорошно възстановяване на обонятелната функция ${ }^{2,3}$. Изкривена обонятелна перцепция също така беше асоциирана като вторична, след прекарани инфекции на ГДП ${ }^{4}$. Доколкото съществуват доказателства за вирусно увреждане на обонятелния епител при тези пациенти ${ }^{5}$, възможно е обонятелните 
значимо със засилване на тежестта на сину-назалното заболяване. Пациентите от УМБАЛ „Царица Йоанна - ИСУЛ“, които са без хроничен риносинуит или носна полипоза (подгрупата УМБАЛЦИ-0), даваха най-много оплаквания от паросмия (изкривено обонятелно възприятие) и аносмия (загуба на обонянието), дължащи се на инфекции на горните дихателни пьтища.

Заключение: Изглежда, че съществува континиум на продължителността и тежестта на обонятелното разстройство при алергичните пациенти, което е паралелно със задълбочаването на тежестта на синуназалното заболяване. В резултат на асоциираната с алергичния ринит повишена честота на развитие на инфекции на горните дихателни пьтища тези пациенти са под риск от увреждане на обонятелния епител. разстройства да са резултат от нарушена обонятелна функция и/или от регенераторни процеси в обонятелните рецептори.

Алергичният ринит се асоциира с обонятелна загуба, която е по-малка от загубата, свързана с хроничен риносинуит и носна полипоза ${ }^{10}$. Настоящето изследване сравнява пациенти с алергичен ринит, чиито основни оплаквания са от обонятелна дисфункция, с пациенти, чиито основни оплаквания са от страна на носа и дишането. Това сравнение се прави с цел характеризиране на връзката между тежестта и продължителността на носното заболяване и възможните увреждания на обонятелната система.

\section{Материал и метод}

\section{Пациенти}

Пациенти от Клиника по УНГ-болести при УМБАЛ „Царица Йоанна - ИСУл““.

Изследването включи 60 пациенти от Клиниката по УНГ-болести при УМБАЛ „Царица Йоанна - ИСУЛ“ анамнестични данни за обонятелно разстройство и доказан алергичен ринит. Оплакванията са от епизодична или продължителна носна конгестия, ринорея, натичане назад на секрети и кихане и поне един позитивен кожен прик тест, свързан с тяхната анамнеза, както ще видим по-долу.

Пациенти от Клиника по детски болести при УМБАЛ „Александровска“.

Група от 30 пациенти на доц. Переновска (групата на децата) с доказан алергичен ринит и/или бронхиална астма, но без наличие на хронично заболяване на носа и околоносните кухини или носна полипоза. Изследването на тези пациенти протече през пролетта и лятото на 2006 r.

\section{Анамнеза}

Разпитът на пациентите включваше субективната оценка на обонятелната им функция, засягаща продължителността на обонятелния проблем, данни за предшестващо изкривено възприятие на миризмите (паросмия), колебания в силата на обонянието и наличието на фантомни миризми - фантосмия (възприятие на миризми, без да е налице действителен стимул). Пациентите бяха разпитвани за наличието на съпътстващи заболявания, свързани с увреждането на обонянието, като: носна полипоза, предшестваща хирургия на околоносните кухини, травма на главата, експозиция на токсични агенти, загуба на обонянието, свързана с инфекции на горните дихателни пътища. Пациентите се разпитваха насочено и за алергичния им ринит - време на поява на симптомите, експозиция към алергени (напр. кучета, котки, акари и фунги) и иританти (напр. тютюнев дим и летливи органични 
съединения). Търсеха се анамнестични данни за бронхиална астма.

\section{Физикален преглед}

Всички изследвани пациенти бяха подложени на оториноларингологичен преглед, като тези, за които се подозираше налично хронично възпаление на носа и околоносните кухини, бяха изследвани рентгенографски или чрез компютърна томография. В групата на пациентите с хронично възпаление влизаха тези с поне две от следните оплаквания: ринорея, назофарингеално натичане на секрет или кашлица повече от 3 месеца; СТ данни за задебелена лигавица и замъгляване на поне един синус. Резултатите от обективното и рентгеновото изследване послужиха за поставяне на пациентите с хронично възпаление в три групи: , 06 - такива без данни за синуит или носни полипи; група „, $\mathrm{S}^{66}$ - тези с доказателства за наличен синуит, но без полипи, и група „Р“6 - пациенти с изявена полипоза при обективния преглед.

\section{Изследване на обонянието}

Проведе се субективно обонятелно тестуване с олфактометьра на Димов-Райков, позволяващ оценката на минималните праговете на усет и разпознаване за пет мирисни субстанции, съотв. цитрал (лимон), гераниол (роза), ацетоацетат (оцет), ментол (мента) и терпениол (миризма на терпентин). Олфактометърът на Димов-Райков включва в набора от тестови миризми и хлороформ, но предвид че се изследваха и деца, последният не бе използван при субективното определяне на обонятелната функция. С помощта на олфактометъра на Димов-Райков определяхме прага на усещане (функция на рецепторната зона) и прага на разпознаване (функция на обонятелните центрове) към споменатите ароматични вещества (одорифери). Принципът на действие на олфактометъра на Димов-Райков е основан на импулсивния метод на Елсберг и Леви. С него е възможно установяването на функцията и на трите черепно-мозъчни нерви, участващи в обонятелната функция - n.olfactorius, n.trigeminus и n.glossopharyngeus. Подредбата на ароматични вещества в олфактометьра: терпениол, гераниол, цитрал, ментол и оцетна киселина е според праговите им концентрации във възходящ ред. За по-голяма прецизност изследванията се провеждаха сутрин (това е особено важно за децата, които лесно се уморяват и губят концентрация) в проветрена стая. Определяхме прага на усещане и прага на разпознаване на тестовите вещества (одорифери), което представлява количествено и качествено субективно изследване на обонянието.
Получените данни се нанасяха на специална бланка - олфактограма, като всеки пациент получаваше собствен обонятелен скор, съотв. за лява и дясна ноздра поотделно.

\section{Алергологични тестове}

Пациентите от Клиниката по детски болести при УМБАЛ „Александровска“ са изследвани алергологично с кожни прик тестове сътветно в алергологичен кабинет на Военно-медицински институт и алергологичен кабинет на Клиника по детски болести при УМБАЛ „Александровска“. Изполваните алергени са: Dermatophagoides farinae (10 000 алергологични единици $[\mathrm{AU}] / \mathrm{ml})$, Dermatophagoides pteronyssinus (10 $000 \mathrm{AU} / \mathrm{ml})$, Alternaria (1:20wt/vol), Aspergillus (1:20wt/vol), Cladosporium (1:20wt/vol), Penicillum mix (1:20wt/ vol), котешки кожен смив (50 $000 \mathrm{AU} / \mathrm{ml})$, кучешки епител (1:20wt/vol).

\section{Анализ на данните}

Ако не се отбелязваше друго, използвахме дескриптивна статистка като средно SE \pm . За сравнение на честотите на разпределение на резултатите от субективното изследване на обонянието, анамнестичните данни за обонятелни разстройства, ринити и други проблеми, свързани с обонятелната дисфункция и резултатите от алергологичното тестуване, използвахме непараметрични тестове (т.нар. $\chi^{2}$ анализ).

Скоровете от обонятелните тестове (средно от резултатите за лявата и дясната ноздри), използвани в анализа, включваха определяне на праговете за усещане и идентификация (разпознаване) на мирисните субстанции. За сравняване на пациентите от Клиника по детски болести при УМБАЛ „Александровска“ (УМБАЛА) с пациентите от Клиника по УНГ болести при УМБАЛ „Царица Йоанна" (УМБАЛЦИ) използвахме вариационен анализ и тестове за независимо сравняване $t$.

\section{Резултати}

\section{Анамнеза и обективно изследване}

60-те пациенти от УМБАЛ „Царица Йоанна“ включваха 35 мъже и 25 жени на възраст от 18 до 74 години (средно $\pm \mathrm{SD}, 51.4 \pm 12.4$ години). 30-те пациенти от Клиника по детски болести при УМБАЛ „Александровска“ (УМБАЛА) включваха 10 момчета и 20 момичета на възраст от 4 до 15 години (средно $\pm \mathrm{SD}, 8.4 \pm 12.4$ години). Таблица 1 показва разпределението на пациентите от УМБАЛ „Царица Йоанна“ (УМБАЛЦИ) по диа- 
гнози (УМБАЛЦИ-0 (пациенти само с обонятелни оплаквания), $\mathrm{n}=30$; УМБАЛЦИ-S (тези с изолиран риносинуит), $n=14$ и УМБАЛЦИ-Р, от които с полипи и хроничен риносинуит $[\mathrm{n}=12]$ и само с полипи $[\mathrm{n}=4], \mathrm{n}=16$. Пациентите от УМБАЛА са сигнификантно по-млади от групата на УМБАЛЦИ $(\mathrm{P}<.001)$. Липсва значима разлика във възрастта на пациентите от трите подгрупи на УМБАЛЦИ, но там съществуват значителни разлики в разпределението по пол $\left(\chi^{2}=9.95, \mathrm{P}=.007\right)$; само 2 -ма $(12 \%)$ от 16-те пациенти с полипи бяха жени, сравнено с 5 -има (36\%) от 14-те пациенти с хроничен риносинуит и 12 (40\%) от 30-те пациенти, които са без хроничен риносинуит и без полипи.

\section{Обонятелна функция}

Средната обонятелна функция спадаше сигнификантно със засилването на признаците на назалното заболяване, което рефлектираше от резултатите при идентификацията на миризмите (F3.84 $=44.83, \mathrm{P}<.001)$ и от резултатите на минималните прагови усещания (F3.84 = 27.10, P<.001). Както се очакваше, има значима връзка между резултатите на лявата и дясната ноздри ( $\mathrm{r}=0.90, \mathrm{P}<.001)$. Като цяло групата на пациентите от УМБАЛА беше нормосмична (среден $\pm \mathrm{SE}$ композитен скор, $6.00 \pm 0.22$ ), въпреки че 9 пациенти от групата на УМБАЛА, които се оплакваха от обонятелна дисфункция, бяха определени като умерено хипосмични (среден $\pm \mathrm{SE}$ композитен скор, $5.67 \pm 0.43$ ). Пациентите от УМБАЛЦИ, всички от които се оплакваха от обонятелна дисфункция, бяха установени като тежки хипосмици (среден $\pm \mathrm{SE}$ УМБАЛЦИ-0 композитен скор, $3.11 \pm 0.45$ ) и аносмици (среден \pm SE УМБАЛЦИ-S композитен скор, $0.93 \pm 0.48$; (среден \pm SE УМБАЛЦЦИ-Р композитен скор, $0.52 \pm 0.28)$, с обонятелна загуба, която сигнификантно нараства със засилване на тежестта на синуназалното заболяване $(\mathrm{P}=.05)$.

Сред пациентите от УМБАЛЦИ съществуваше слаба асоциация между наличието на синуназално страдание и установената при обективното изследване проходимост на носните ходове $\left(\chi^{2}=4.36, \mathrm{P}=\right.$ $.04)$. Честотата на видимата проходимост на носните ходове бе значително по-ниска при пациентите с данни за риносинуит (подгрупите УБАЛЦИ-S И УМБАЛЦИ-Р комбинирано). Единият или двата носни хода бяха видимо проходими само при 19 $(63 \%)$ от тези пациенти, сравнено с 26 пациенти $(87 \%)$ от подгрупата УМБАЛА-0 (таблица 1$)$. Понататъшният анализ на композитните обонятелни скорове показа, че нито проходимостта на носните ходове, нито тяхната връзка с моментното състояние на синуназалното заболяване сигнификантно оказва влияние върху обонятелната функция; т.е. моментното състояние на синуназалното заболяване оказва значим ефект върху обонятелната функция, но въпреки че проходимостта на носните ходове е във връзка със статуса на заболяването, тя не представлява значим фактор за обонятелната функция.

Средните композитни обонятелни скорове за всяка подгрупа на пациентите от УМБАЦИ беше сигнификантно по-ниска от предвиденото за тяхната възрастова група ( $\mathrm{t}, 7.24-20.05 ; \mathrm{P}<.001)$. Средните композитни скорове на пациентите от УМБАЛА също бяха значимо по-ниски от очакваното за тяхната възрастова група $(\mathrm{t}=2.36, \mathrm{P}=.01)$.

Анамнестично докладваната продължителност на обонятелна загуба на пациентите от УМБАЛЦИ значимо се увеличаваше с утежняването на синуназалното заболяване $(\mathrm{F} 2.57=4.35, \mathrm{P}=.02)$. Докладваната продължителността на обонятелните проблеми при пациентите, страдащи единствено от алергичен ринит (УМБАЛЦИ-0), бе значимо по-кратка от тази на пациентите, страдащи от хроничен риносинуит в комбинация с хроничен ринусинуит (УМБАЛЦИ-S) или носни полипи (УМБАЛЦИ-Р) (P=.05). Самостоятелно докладваната продължителност на назалната симптоматика не се различаваше значимо между пациентите от 3-те подгрупи на УМБАЛЦИ. Типичният пациент от групата УМБАЛЦИ е страдал от назална симптоматика от $20.6 \pm 2.4$ години (средно $\pm \mathrm{SE}$ ), което е сигнификантно по-дълго от типичния

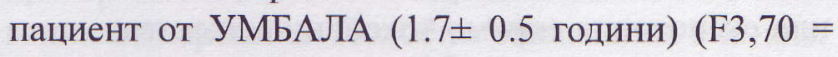
13.57, $\mathrm{P}<.001)$.

Да разгледаме честотата на разпределение на обонятелната симптоматика сред 30 пациенти От УМБАЛА, 30 пациенти от УМБАЛЦИ-0 и комбинацията от 30 пациенти от УМБАЛЦИ-S и УМБАЛЦИ-Р. Сравнено с другите 2 пациентски подгрупи, болните от УМБАЛЦИ-0 даваха по-висока честота на обонятелни оплаквания (14 [47\%], сравнено с 3-ма [10\%] от 30-те пациенти от всяка от другите групи $\left.\left[\chi^{2}=15.56, \mathrm{P}<.001\right]\right)$. Заедно подгрупите УМБАЛЦИ-S и УМБАЛЦИP докладваха значително по-голяма честота на флуктуации в обонятелното възприятие (22-ма пациенти [73\%], сравнено с 10 болни [33\%] от УМБАЛА и 13 пациенти [43\%] при пациентите от УМБАЛЦИ-0 $\left[\chi_{2}=10.40, \mathrm{P}=.006\right]$. Честотата на оплаквания от фантосмия нямаше значима разлика между различните пациентски групи.

Изследвахме връзката между всеки един от признаците на обонятелна дисфункция и проходимостта на носните ходове в процеса на синуназално заболяване. Открихме, че от пациентите от 
подгрупата УМБАЛЦИ-0, които са без синуназално страдание, значимо по-чести оплаквания от паросмия дават тези с проходими носни ходове в сравнение с тези, при които бяха запушени и двете ноздри $\left(\chi^{2}=4.04, \mathrm{P}=.04\right)$. Всъщност само 4-ма (13\%) от УМБАЛЦЦ-0 бяха с назална обструкция и никой от тях не се оплакваше от качествени обонятелни нарушения.

\section{Данни от анамнезата, които са свързани със загуба на обонянието}

Заедно пациентите от УМБАЛА-S и УМБАЛА$\mathrm{P}$ даваха сигнификантно повече анамнестични данни за носна полипоза (15 [50\%] от 30) и синусна хирургия (22 [73\%] от 30$)$ в сравнение с пациентите от която и да е от другите две групи $\left(\chi^{2}=14.48, \mathrm{P}<.001\right.$ и съответно $\chi^{2}=11.294, \mathrm{P}=$ .004). Пациентите от всяка УМБАЛЦИ подгрупа даваха значително по-висока честота на обонятелна загуба, асоциирана с инфекции на горните дихателни пътища (17 [57\%] от УМБАЛЦИ-0 и 8 [27\%] от болните от подгрупите УМБАЛЦИ-S и УМБАЛЦИ-Р), сравнено с пациентите от групата на УМБАЛА $\left(\mathrm{n}=2[7 \%] ; \chi^{2}=18.10, \mathrm{P}<.001\right)$. Пациентите от УМБАЛА имаха по-висока честота на бронхиална астма (15 [50\%] от 30$)$ в сравнение с пациентите от подгрупите на УМБАЛЦИ (5 [17\%] от УМБАЛЦИ-0 и 10 [33\%] от болните от подгрупите УМБАЛЦИ-S/УМБАЛЦИ-Р; $\chi^{2}=7.50, \mathrm{P}=$ .02). Анамнестично пациентите от тези подгрупи не се различаваха по честота на травма на главата или експозиция спрямо токсични вещества.

Както вече споменахме 7,8 , ние също така открихме, че оплакванията на пациентите от всички подгрупи на УМБАЛЦИ от изкривено обонятелно въ3приятие (паросмия) са асоциирани сигнификантно с анамнестични данни за прекарани инфекции на горните дихателни пътища $(\mathrm{n}=90)\left(\chi^{2}=7.65, \mathrm{P}=\right.$ .006) и в частност подгрупата УМБАЛЦИ-0 $\left(\chi^{2}=\right.$ $5.13, \mathrm{P}=.02)$.

\section{Кожсни тестове}

Пациентите от групата УМБАЛА бяха изследвани алергологично в алергологичните кабинети на УМБАЛ, „Александровска“" и Военно-медицинския институт, а тези от УМБАЛЦИ - от др.Шишенкова в УМБАЛ „Царица Йоанна“. Установиха се малки разлики в резултатите от кожните тестове сред пациентите от трите подгрупи на УМБАЛІЦИ. Алергичното тестуване показа, че няма разлики, когато алергените бяха групирани на целогодишни (средно 87\% от пациентите на всяка подгрупа бяха определени като позитивни към акари, котки, кучета и/или фунги) или сезонни (средно
$84 \%$ от пациентите на всяка подгрупа бяха определени като позитивни към тревни и дървесни полени). Имаше обаче значителни разлики при някои индивидуални тестувания. За няколко пациенти от групата УМБАЛЦИ беше установено, че са позитивни срещу кучешки антигени (16 [53\%] УМБАЛЦИ-0 и 8 [28\%] от подгрупите УМБАЛЦИ-S/УМБАЛЦИ-Р, в сравнение с 21 [70\%] пациенти от УМБАЛА; $\left.\chi^{2}=10.75, \mathrm{P}=.005\right)$ и към тревни полени (17 [57\%] УМБАЛЦИ-0 и 15 [50\%] от подгрупите УМБАЛЦИ-S/УМБАЛЦИ-Р в сравнение с 26 [87\%] пациенти от УМБАЛА; $\chi^{2}$ $=9.99, \mathrm{P}=.007$ ).

\section{Коментар}

Изследвахме обонятелната функция на пациенти с алергичен ринит. В изследването включихме група от пациенти от УМБАЛ „Александровска“ (УМБАЛА), чиито първични оплаквания не включваха обонятелна дисфункция, и група на пациенти от УМБАЛ „Царица Йоанна - ИСУЛ (УМБАЛЦИ), оплакващи се основно от загуба на обонянието. Открихме, че втората група пациенти (УМБАЛЦИ) е по-възрастна от първата, възникването на назалната симптоматика е по-отдавна, резултати от изследването на обонянието са пониски и по-често имат анамнестични данни за наличие на сину-назално заболяване в сравнение с пациентите от групата УМБАЛА.

Открихме също така, че разпределението по пол между пациентите от УМБАЛЦИ не е еднакво. Докато в групата на пациентите, страдащи само от алергичен ринит (УМБАЛЦИ-0), жените са малко повече от мъжете, в групата на пациентите с хроничен риносинуит (УМБАЛЦИ-S) съотношението мъже - жени е 2:1, като достига 7:1 сред пациентите, страдащи от носна полипоза (УМБАЛЦИ-Р). Съществува континиум на обонятелните нарушения сред всички пациенти с алергичен ринит от тези без сину-назално заболяване до тези с хронични риносинуити и тези, страдащи от носна полипоза (мнозинството от които също са с риносинуит). Пациентите, засегнати единствено от алергичен ринит, имат тенденция да проявяват по-умерени обонятелни нарушения. Въпреки че пациентите от УМБАЛА бяха по-млади, а както е известно обонятелният усет намалява с възрастта $^{13}$, едно сравнение с контролна група показва че единствено процесите на стареене не могат да бъдат обвинени за обонятелните нарушения, открити при пациентите от групата УМБАЛЦИ. Както е видно от фигура 1, показанията от олфактометриите на пациентите от УМБАЛЦИ е зна- 
чително по-ниска от предполагаемите резултати за хората от тяхната възраст. Интересно е, че и резултатите от групата на пациентите от УМБАЛА също са значително по-ниски от очакваните за тяхната група, въпреки че като цяло тази група бе определена като нормосмична.

Назалната обструкция, оценена от обективния преглед на носа (предна риноскопия), е свързана сигнификантно, макар и слабо с наличието на синуназално заболяване. Въпреки това не открихме връзка между проходимостта на носните ходове и обонятелната функция, както между впрочем и в други изследвания ${ }^{10}$. В най-добрия случай обективната находка на носните ходове спомага за грубо ориентиране в диагностицирането на назалната обструкция. Дори обективни изследвания като акустичната ринометрия, проведена от други автори, не открива връзка между обструкцията и обонятелната дисфункция ${ }^{8,9}$.

Интересно е да се отбележи, че продължителността и тежестта на обонятелната загуба се свързват с тежестта на сину-назалното заболяване, но не и с продължителността на носната симпотматика сама по себе си. Доколкото загубата на обонянието се приема за една от проявите на сину-назално заболяване ${ }^{1}$, нашите резултати показаха, че 9тимата пациенти от групата УМБАЛА, които вече се бяха оплакали от обонятелно разстройство, вероятно ще развият пълната картина на риносинуит в бъдеще.

Значим брой от изследваните в това проучване пациенти от групата УМБАЛЦИ дадоха анамнестични данни за прекарана вирусна респираторна инфекция, което може би не неочаквано, тъй като известно е, че алергичният ринит се асоциира с по-чести инфекции на дихателните пътища ${ }^{14}$. Съществуват хистологични данни от човешка обонятелна лигавица ${ }^{5}$, говорещи за наличието на найчесто необратими увреждания в нея, получени от вирусни инфекции, като степента на обонятелната дисфункция корелира със степента на епителните увреждания. Нарушенията в обонятелното възприятие, които би могло да се дължат на епително увреждане, се докладват предимно от пациенти, чиято обонятелна загуба се асоциира с вирусна инфекция на дихателните пътища ${ }^{7,8}$.

От пациентите, участвали в нашето изследване, най-висока честота на обонятелни разстройства и анамнестични данни за вирусни инфекции на горните дихателни пътища бяха докладвани от пациентите с най-ниска честота на налична носна обструкция. Тези данни подсказват, че връзката между алергичния ринит и обонятелното нарушение може отчасти да се дължи на по-честите вирусни инфекции на дихателните пътища, предизвикани от патофизиологичните характеристики на алергичния ринит, а не само от наличието на възпаление, какъвто е случаят с носната полипоза. Това може да обясни също така защо прилагането на назални кортикостероиди за лечение на обонятелна загуба, асоциирана с риносинуит, е неефективно при значителен брой пациенти ${ }^{1}$.

Сред нашите пациенти честотата на докладваните от самия пациент флуктуации в обонятелната чувствителност се увеличаваше с утежняване на сину-назалното заболяване. Честотата на оплакванията от изкривено възприемане на обонятелните стимули обаче бе по-висока при пациентите с по-малко сериозно заболяване. Възможно е този тип обонятелни разстройства да възникват по време на възстановителната фаза от инфекции на горните дихателни пътища (възможно е дегенерацията (или регенерацията) на обонятелния епител временно да предизвиква изкривени обонятелни възприятия ${ }^{15}$ ). Това може би обяснява защо групата на пациентите без заболяване на синусите и без полипи (фактически групата на пациенти с алергичен ринит) даваше най-много оплаквания от паросмия (изкривено обонятелно възприятие), при които също така процентът на обонятелна загуба, асоциирана с инфекции на ГДП, бе найвисок. Групата на пациентите с хронично заболяване на синусите и на тези, страдащи от носна полипоза, също даваше анамнестични данни за прекарани инфекции на ГДП, но липсваха оплаквания от паросмия. Подобни оплаквания е имало, но в началото на техните заболявания.

Систематичното изследване на пациенти с изолиран алергичен ринит и на такива с хронично синуназално заболяване ни насочи към два детайла от анамнезата, които биха могли да са ни от полза при детерминирането на причината за обонятелното разстройство: пациентите, оплакващи се от флуктуации в обонятелната чувствителност, са статистически значимо свързани с предимно обструктивно сину-назално заболяване, докато пациентите, докладващи изкривено обонятелно възприятие, са статистически значимо свързани с вирусни инфекции на респираторния тракт. При пациентите с алергичен ринит продължителността и тежестта на обонятелната загуба се асоциират с по-тежкото протичане на сину-назално заболяване. Тези пациенти са с повишен риск от загуба на обонянието, понеже алергичният ринит улеснява развитието на рецидивиращи инфекции на респираторния тракт, които от своя страна водят до увреждане на обонятелния епител. 


\section{Литература:}

1. Марев, Д. Ринит в детском возрасте: ефективност и безвредность нового интраназального кортикостероида." J. Folia Otorhinolaryngologiae", S. Petersburg, Russia, vol. 9, №.1-2, 58-60, 2003.

2. Mott AE, Cain WS, Lafreniere D, et al. Topical corticosteroid treatment of anosmia associated with nasal and sinus disease. Arch Otolaryngol Head Neck Surg. 1997; 123: 367-372.

3. Goodspeed RB, Catalanotto FA, Gent JF, et al. Clinical characteristics of patients with taste and smell disorders. In: Meiselman HL, Rivin RS, eds Clinical Measurement of Taste and Smell. New York, NY: Macmillan Publishing Co; 1986: 451-466

4. Nordin S, Murphy C, Davidson TM, et al. Prevalence and assessment of qualitative olfactory dysfunction in different age groups. Laryngoscope. 1996; 106: 739-744

5. Cowart BJ, Young IM, Varga EK, Lowry LD. The natural history of smell dysfunctions secondary to upper respiratory infection (URI) [abstract]. Chem. Senses. 1998; 23: 608.

6. Jafek BW, Hartmann D, Eller PM, et al. Postviral olphactory dysfunction. Am J Rhinol. 2007; 4: 91-100.

7. Fein BT, Kamin PB, Fein NN. The loss of smell and taste in nasal allergy. Ann Allergy Asthma Immunol. 2003; 24: 278-283.

8. Apter AJ, Mott AE, Cain WS, et al. Olfactory loss and allergic rhinitis. J Allergy Clin Immunol. 2005; 90:670-680.
9. Cowart BJ, Flynn-Rodden K, McGeady SJ, Lowry LD. Hyposmia in allergic rhinitis. J Allergy Clin Immunol. 2001; 91: 747-751.

10. Meltzer EO, Jalowayski AA, Orgel HA, Harris AG. Subjective and objective assessements in patients with seasonal allergic rhinitis: effects of therapy with mometasone furoate nasal spray. J Allergy Clin Immunol. 2006; 102:39-49

11. Apter AJ, Mott AE, Clive J. Allergic rhinitis and olfactory loss. Ann Allergy Asthma Immunol. 2007; 75: 311-316.

12. Cain WS, Gent JF, Goodspeed RB, Leonard G. Evaluation of olfactory dysfunction in the Connecticut Clinical research Center. Laryngoscope 1988: 98 : 83-88.

13. Moloney JR. Nasal polyps, nasal polypectomy, asthma and aspirin sensitivity: their association in 445 cases of nasal polyps. J Laryngol Otol. 1977; 91: 837-846.

14. Cain WS, Gent J. Olfactory sensitivity: reliability, generality and association with aging. J Exp Psychol Hum Percept Perform. 1991; 17:382-391.

15. Naclerio R, Solomon W. Rhinitis and inhalant allergens. JAMA. 2005; 278: $1842-1848$.

16. Leopold D. Distorted olfactory perception. In Doty RL, ed. Handbook of Olfaction and Gustation. New York, NY: Marcel Dekker Inc; 2002 441-454. 